\title{
Effect of the crystallinity of NCD and MLD diamond coatings characterized by same level of residual stresses after annealing on their fatigue strength and wear behavior in milling
}

\author{
Georgios Skordaris ${ }^{1,}$, , Tilemachos Kotsanis ${ }^{1}$, Apostolos Boumpakis ${ }^{1}$, and Fani Stergioudi ${ }^{2}$ \\ ${ }^{1}$ Laboratory for Machine Tools and Manufacturing Engineering, Mechanical Engineering \\ Department, Aristotle University of Thessaloniki, Greece \\ ${ }^{2}$ Physical Metallurgical Laboratory, Mechanical Engineering Department, Aristotle University of \\ Thessaloniki, Greece
}

\begin{abstract}
Nano-composite (NCD) and multi-layered (MLD) diamond coatings were deposited on cemented carbide tools using hot filament chemical vapour deposition (HFCVD) techniques. Appropriate annealings were conducted on the examined diamond coatings in order to be characterized by the same level of residual stresses. The crystalline structure of the employed diamond coatings was investigated by conducting Raman spectra. Inclined impact tests at ambient and elevated temperatures were carried out for assessing their temperature-dependent fatigue strength. Moreover, the wear behaviour of diamond coated inserts was investigating in milling aluminum foam. Raman spectra were also conducted on the treated diamond coatings for capturing potential crystalline changes developed due to the exercised thermal and dynamic mechanical loads during cutting. According to the attained results, the coexistence of $\mathrm{sp}^{2}-$ and $\mathrm{sp}^{3}$-bonded phases in the cases of MLD diamond coatings results in an accelerated wear development, despite their structure capability to decelerate the crack propagation. As a result, nano-crystalline diamond coatings characterized only by $\mathrm{sp}^{3}$-bonded phase exhibit an improved wear behaviour. The cutting performance of the NCD coated inserts is further improved due to the enhanced tribological properties of the NCD coatings.
\end{abstract}

\section{Introduction}

Nano-composite (NCD) and multi-layered (MLD) diamond coatings can be effectively applied in machining of nonferrous materials such as of aluminium alloys, carbon fibre reinforced plastics etc. [1-4]. Due to the superior adhesion characteristics of microcrystalline diamond layers and to improved tribological properties of nano-crystalline diamond ones, various micro- and nano-crystalline layer coating systems on cemented carbide substrates are manufactured and used effectively in machining procedures $[5,6]$.

\footnotetext{
*Corresponding author: skordaris@meng.auth.gr
} 
Moreover, recent investigations revealed that MLD coatings withstand more effectively the repetitive impacts during milling than the NCD ones, since the layer's interfaces obstruct the crack propagation. Thus, MLD coatings are characterized by reduced brittleness and improved cutting performance [4].

A significant issue affecting the brittleness of the produced diamond coatings is the level of residual stresses in the film structure [4]. The high level of residual stresses in the diamond film structure is attributed to epitaxial crystal differences (structural stresses) and thermal expansion coefficients mismatch of the diamond coating and its cemented-carbide substrate (thermal stresses) [4,7]. An effective way to reduce the structural residual stresses in the diamond film structure is attained by appropriate annealing. In the frame of this work, NCD and MLD coatings were produced and appropriately annealed in vacuum at a temperature of $400^{\circ} \mathrm{C}$ for possessing the same level of residual stresses [8]. As a result, by decoupling the effect of residual stresses in the diamond film structure on the films' fatigue strength, the impact of a nano-crystalline structure or a combination of nano- and microcrystalline diamond layers on the wear behaviour of diamond coated tools was assessed.

\section{Experimental details}

Cemented-carbide inserts of HW-K05/K20 SPGN120308 ISO specifications were coated with nano-composite (NCD), or multi-layered (MLD) films of approximately $5 \mu \mathrm{m}$ thickness via the hot filament method using a CC800/9Dia CEMECON coating machine. Cobalt-etching procedures were carried out prior to diamond coating deposition for attaining sufficient adhesion [1]. The MLD coatings consist of ten successive and alternate nano- and micro-structured layers. These nano- and micro-structured layers had approximately 0.34 and $0.66 \mu \mathrm{m}$ thickness, respectively.

The fatigue strength of the NCD and MLD coated cemented-carbide inserts was investigated by conducting inclined impact tests at temperatures of $25^{\circ} \mathrm{C}$ and $300^{\circ} \mathrm{C}$ [4]. The impact tester device was designed and manufactured by the Laboratory for Machine Tools and Manufacturing Engineering of the Aristotle University of Thessaloniki in conjunction with the company Impact-BZ (see figure 1a) (London, UK) $[9,10]$. The Raman spectroscopy on the untreated as well as treated diamond coatings was carried out using a LabRAM HR spectrometer. The milling investigations were conducted employing a threeaxis numerically-controlled milling center using aluminum foam as workpiece material. This workpiece material consists of various hard phases, as related optical microscopy observations using standard metallographic techniques revealed (see figure 1b). Moreover, due to the structure of the workpiece material, intense dynamic loads are developed on the cutting edge of the coated tools during cutting.
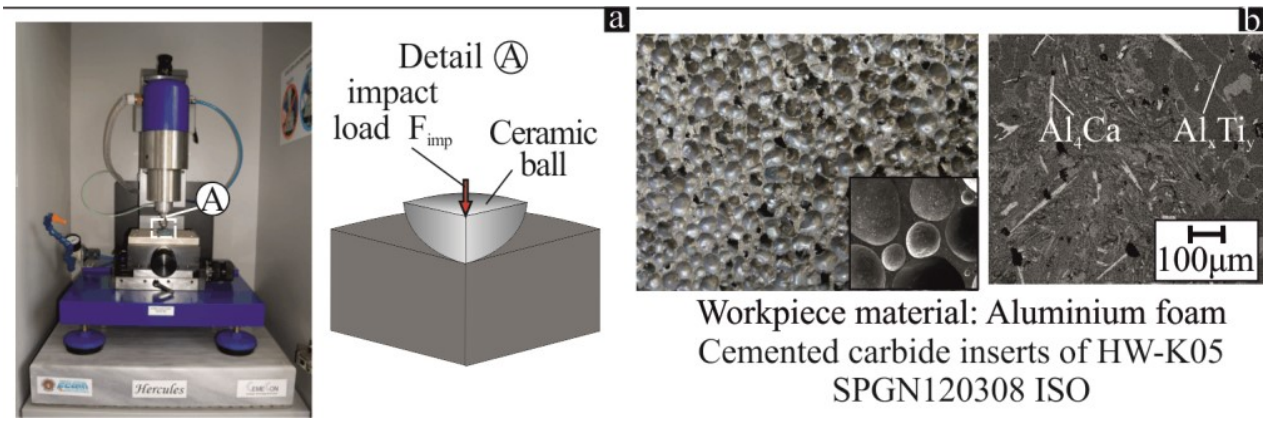

Workpiece material: Aluminium foam

Cemented carbide inserts of HW-K05 SPGN120308 ISO

Fig. 1. (a) The employed impact tester for conducting experiments; (b) the workpiece material used in milling experiments. 


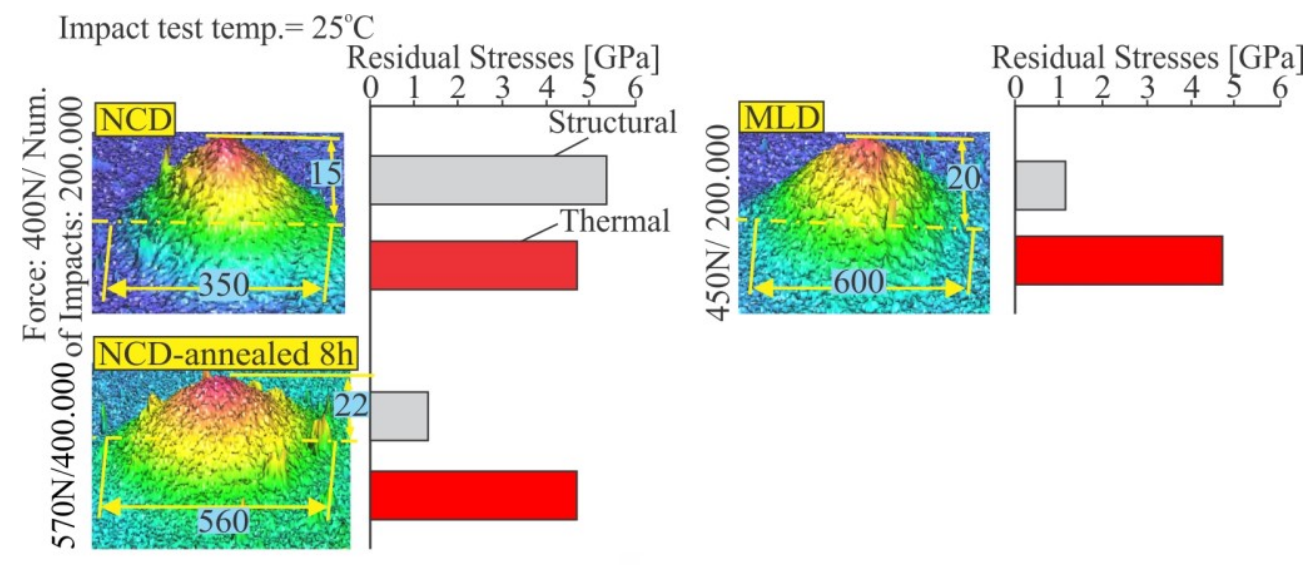

Diamond film: $\mathrm{t} \approx 5 \mu \mathrm{m}, \mathrm{Rz} / \mathrm{Rt}=1 / 1.2 \mu \mathrm{m}, \mathrm{E}=1100 \mathrm{GPa}$

Substrate: HW-K05/K20, E=580 GPa, $\mathrm{S}_{\mathrm{Y}} / \mathrm{S}_{\mathrm{M}}=3.3 / 5.8 \mathrm{GPa}$

Fig. 2. Determined thermal and structural residual stresses in the investigated diamond film cases after inclined impact tests.

\section{Characterization of the investigated diamond coatings}

\subsection{Residual stresses}

For determining the overall residual stresses in the investigated diamond film cases, inclined impact tests at various loads and cycles were conducted at room temperature. A fatigue damage of the diamond coating-substrate interface develops after a certain number of repetitive impacts depending on the impact load. After the interface fatigue failure, the high compressive residual stresses of the diamond structure are released, and the detached coating hikes up at a certain maximum height (bulge formation). Based on a developed FEA model described analytically in [11], which simulates the film lifting after the fatigue failure of its interface and the residual stress release, the overall residual stresses in the film structure were calculated (see figure 2). Moreover, the thermal residual stresses were determined with the aid of an additional FEA model [11]. These stresses are shown in figure 2 .
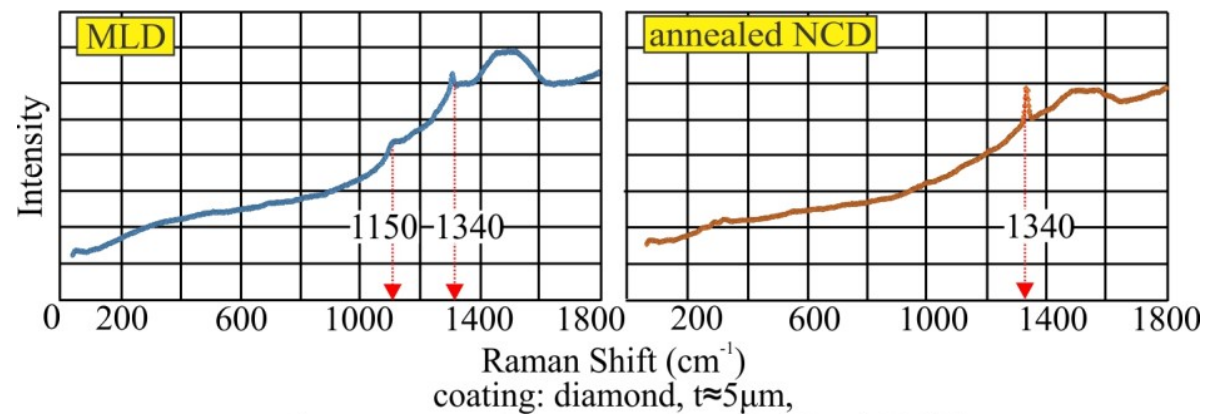

coating: diamond, $\mathrm{t} \approx 5 \mu \mathrm{m}$,

substrate: $\mathrm{HW}-\mathrm{K} 05$, Temperature: $25^{\circ} \mathrm{C}$ and $300^{\circ} \mathrm{C}$

Fig. 3. Raman spectra of the investigated MLD and annealed NCD films. 


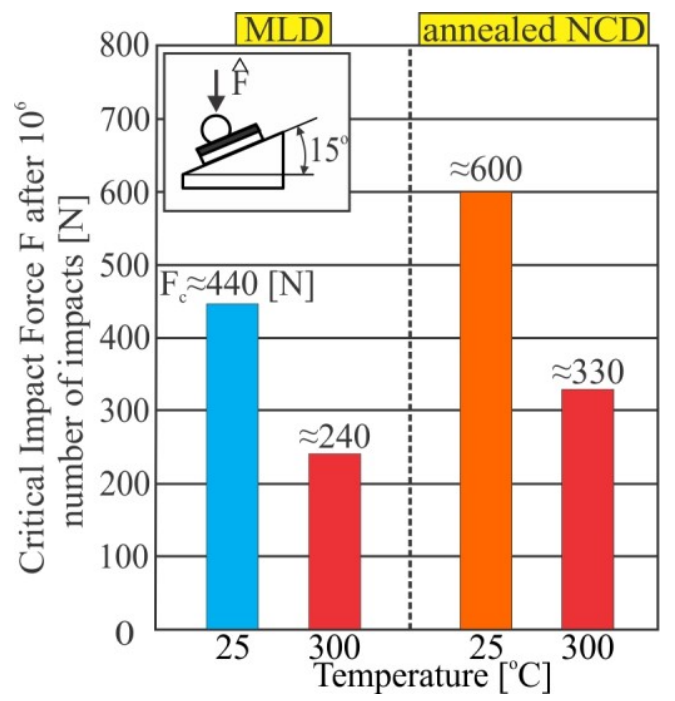

Fig. 4. Determined critical impact force for avoiding coating damage after $10^{6}$ impacts at $25^{\circ} \mathrm{C}$ and $300^{\circ} \mathrm{C}$.

As it can be observed, NCD coatings are characterized by a comparably larger amount of residual stresses in the film structure. In order for both coating types to possess the same amount of residual stresses, NCD coatings were annealed in vacuum at a temperature of $400^{\circ} \mathrm{C}$ for a duration of $8 \mathrm{~h}$. Due to the applied annealing procedure, a portion of the structural stresses is released, whereas the thermal residual stresses in the diamond film structure remain invariable. As a result, both MLD and NCD coatings are characterized by the same level of residual stresses.

\subsection{Crystallinity}

The crystallinity of the produced diamond coatings was characterized by conducting Raman spectroscopy. The recorded spectra are presented in figure 3. Both MLD and annealed NCD films exhibit a narrow peak at around $1340 \mathrm{~cm}^{-1}$ confirming the high diamond crystalline quality of the coatings and the existence of an $\mathrm{sp}^{3}$-bonded phase $[12,13]$. One more peak appears pronounced at roughly $1150 \mathrm{~cm}^{-1}$ in the Raman spectra of the MLD coated specimens. This extra feature originates from co-existing $\mathrm{sp}^{2}$-phases, called as trans polyacetylene. The trans polyacetylene possesses obviously inferior strength properties compared to the $\mathrm{sp}^{3}$-bonded phases. As a consequence, a decomposition of the $\mathrm{sp}^{2}$-bonded trans polyacetylene phases takes place when repetitive thermal and mechanical loads both leading to elastic film deformations are simultaneously applied. This could happen during the cutting procedure [13].

\subsection{Fatigue}

For evaluating the fatigue strength of the MLD and the annealed NCD coatings, inclined impact tests were carried out at ambient temperature and at $300^{\circ} \mathrm{C}$. The critical impact force for fatigue failure of the examined diamond coatings at $25^{\circ} \mathrm{C}$ and $300^{\circ} \mathrm{C}$ is displayed in figure 4 . In both examined coating cases, an increase of the operational temperature results in a deterioration of the fatigue strength. Moreover, NCD coatings possess an improved fatigue strength compared to MLD ones, when both coatings are characterized by the same level of residual stresses and thus brittleness. 


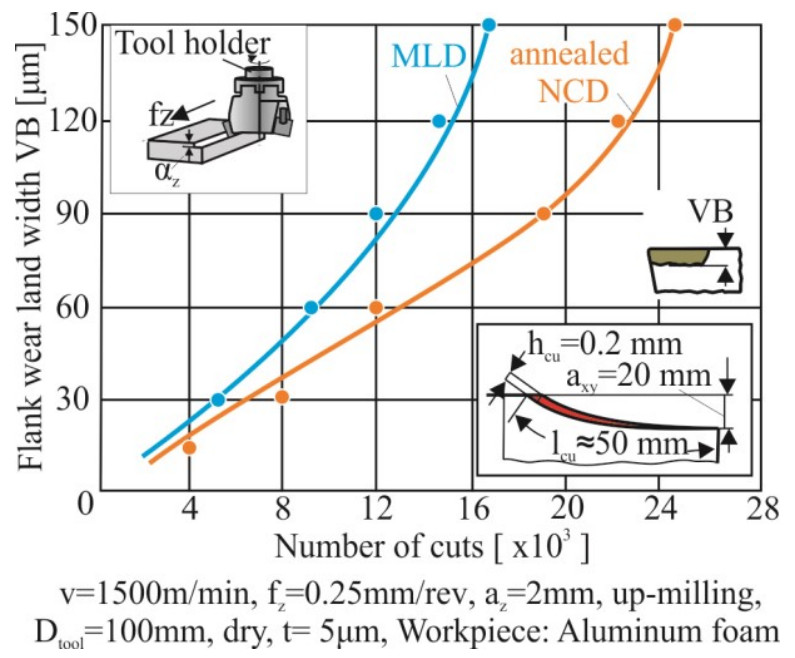

Fig. 5. Flank wear development versus the number of cuts of the investigated diamond coated inserts.

\section{Cutting performance of the diamond coated inserts in milling and explanation of the obtained results}

The cutting performance of the manufactured diamond coated inserts was investigated in milling without coolant or lubricant for attaining a more intense wear evolution. After a prescribed number of successive cuts, the cutting insert wear was recorded. In the case of the NCD coated inserts, after approximately 24000 cuts, a flank wear width of $0.15 \mathrm{~mm}$ developed (see figure 5). Compared with this, the wear behavior of the MLD coated inserts characterized by the same level of residual stresses after annealing worsens significantly. More specifically, the MLD coated inserts managed to cut only approximately 16000 cuts up to the same flank wear width. The obtained larger number of cuts when annealed NCD inserts are used exhibit their superior wear resistance compared to the MLD ones.

In order to explain these results, Raman spectroscopy was conducted on the remaining coatings on the tool rake after milling (see figure 6). In this way, potential crystallinity changes of the diamond coatings due to the exercised thermal and mechanical loads could be captured. In the case of the MLD coatings, the weaker spectral peaks in the diagram of figure 6 indicate a decomposition of the trans polyacetylene $\mathrm{sp}^{2}$-bonded phases (peaks at
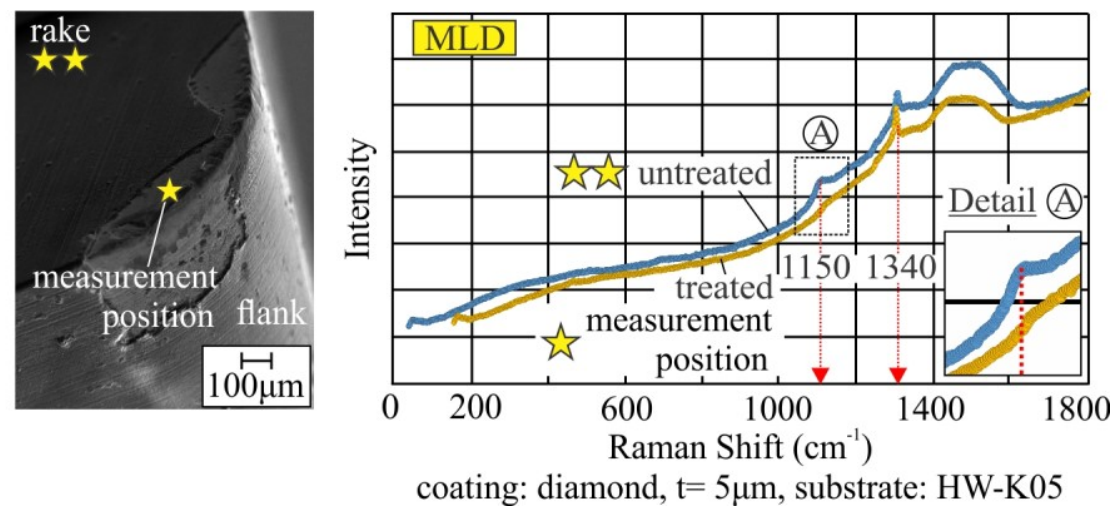

Fig. 6. Raman spectra of the remaining coating for MLD film case after milling. 
around $1150 \mathrm{~cm}^{-1}$ ), when thermal and mechanical loads during milling are simultaneously applied. Consequently, a diamond coating strength weakening arises resulting in a more rapid wear evolution compared to NCD coatings during the cutting processes.

\section{Conclusions}

In this paper, the effect of the structure of NCD and MLD coatings characterized by the same level of residual stresses after annealing on their fatigue strength and wear behaviour was investigated. In this context, NCD coated inserts were annealed in vacuum at a temperature of $400^{\circ} \mathrm{C}$ for $8 \mathrm{~h}$ for possessing the same level of residual stresses as the MLD coated ones. Thus both coatings are characterized by the same brittleness. Based on the attained impact and milling results, when mechanical and thermal loads are simultaneously exercised, the decomposition of an $\mathrm{sp}^{2}$-bonded trans polyacetylene phases, existing in the MLD diamond coating structure, leads to more intense wear compared to a trans polyacetylene free NCD film. Moreover, the improved tribological properties of the NCD coatings further enhance their cutting performance.

This research is co-financed by Greece and the European Union (European Social Fund- ESF) through the Operational Programme «Human Resources Development, Education and Lifelong Learning 2014-2020» in the context of the project "Optimization of the cutting performance of nanoand micro- structured diamond coatings via appropriate thermal treatments" (MIS 5047906).

\section{References}

1. R. Haubner, W. Kalss, NT J REFRACT MET H, 28: 475-483, (2010)

2. E-G Ng, D. Szablewski, M. Dumitrescu, M.A. Elbestawi, J.H Sokolowski, CIRP ANN - MANUF TECHN, 53: 69-72, (2004)

3. R. Polini, Thin Solid Films 515: 4 - 13, (2006)

4. G. Skordaris, K.-D. Bouzakis, P. Charalampous, T. Kotsanis, E. Bouzakis, O. Lemmer, CIRP ANN - MANUF TECHN, 65, pp. 101-104, (2016)

5. R. Dumpala, N. Kumar, CR Kumaran, S. Dash, B. Ramamoorthy, Ramachandra Rao MS, Diam. Relat. Mater., 44:71-77, (2014)

6. R. Dumpala, M. Chandran, N. Kumar, S. Dash, B. Ramamoorthy, Ramachandra Rao MS, Int. J. Refract. Met. H, 37:127-133, (2013)

7. N. Woehrl, T. Hirte, O. Posth, V. Buck, Diam. Relat. Mater., 18: 224-228, (2009)

8. M H Staia, M D'Alessandria, D T Quinto, F Roudet, M Marsal Astort, J. Phys.: Condens. Matter, 18: S1727-S1736, (2006)

9. Available online: www.impact-bz.com

10. G. Skordaris, F. Stergioudi, A. Boumpakis, D. Stergioudi, COATINGS, 9, 855, (2019)

11. K.-D. Bouzakis, G. Skordaris, E. Bouzakis, S. Makrimallakis, S. Kombogiannis, O. Lemmer, Surf. Coat. Technol., 237, pp. 135-141, (2013)

12. AC Ferrari, J. Robertson, Phys. Rev. B., (2001)

13. G. Skordaris, K.-D. Bouzakis, T. Kotsanis, A. Boumpakis, F. Stergioudi, D. Christofilos, O. Lemmer, W. Kölker, M. Woda, CIRP ANN - MANUF TECHN, 68: 65-68, (2019) 